\title{
Knowledge, Attitude and Practices of Diabetic Retinopathy in Diagnosed Diabetic Patients: A Descriptive Study
}

\author{
Faryal Farooq ${ }^{1 *}$,Shahid Hussain Bapar ${ }^{2}$ \\ ${ }^{1}$ Al-Farooq Memorial Eye Clinic Chichavatni Pakistan \\ ${ }^{2}$ Nursing Instructor, Federal General Hospital Islamabad
}

DOI: $\underline{10.36348 / \text { sjmps.2021.v07i01.003 }}$

| Received: 11.12.2020 | Accepted: 21.12.2020 | Published: 08.01.2021

*Corresponding author: Faryal Farooq

\section{Abstract}

\begin{abstract}
Aim: To determine Knowledge, attitude and practices (KAP) about Diabetic Retinopathy in diagnosed Diabetic patients at outpatient department of district head quarter hospital Sahiwal Pakistan. Introduction: Diabetic Retinopathy is a diabetes complication that affects eyes. It is caused by damage to the blood vessels of the light sensitive tissue at the back of the eye (retina). The longer you have diabetes and the less controlled your blood sugar is, the more likely you are to develop this eye complication. Methodology: This was hospital based, descriptive, cross sectional study. A written informed consent was taken from the all patients to take part in this study. Data was analyzed by using statistical package for social sciences SPSS version 24. Results: In this study 72 patients were included out of which $30(41.7 \%)$ were male and $42(58.3 \%)$ were female. Out of these 72 , majority $42(58.3 \%)$ patients had no knowledge about diabetes and only 30 $(41.7 \%)$ patients had good knowledge regarding diabetic retinopathy. Conclusion: In this study, knowledge about diabetic retinopathy was not as satisfactory. Knowledge about Diabetic retinopathy was even lower than diabetes. Results for practices were totally different from knowledge. Practices for controlling diabetes regarding diet was good but regarding exercise showed poor results.

Key words: Knowledge, Diabetes, Diabetic Retinopathy, Attitude, Prevention, Practices, Control of Disease.

Copyright (C) 2021 The Author(s): This is an open-access article distributed under the terms of the Creative Commons Attribution 4.0 International License (CC BY-NC 4.0) which permits unrestricted use, distribution, and reproduction in any medium for non-commercial use provided the original author and source are credited.
\end{abstract}

\section{INTRODUCTION}

Diabetes is a disease that occurs when blood glucose level is high in the blood [1]. Diabetic Retinopathy is a diabetes complication that affects eyes. It is caused by damage to the blood vessels of the light sensitive tissue at the back of the eye (retina). The longer you have diabetes and the less controlled your blood sugar is, the more likely you are to develop this eye complication [2]. Diabetic Retinopathy (DR) is a well recognized complication of diabetes mellitus. Out of 39 million global blindness is caused by various eye diseases and $4.8 \%$ (1.8 million) is due to DR. Nationally every fourth patient with diabetes has some level of DR [3].

Diabetes has been considered as one of the largest health emergencies of recent times [4]. There were 415 million people suffering from diabetes in the world in 2015 and this number is expected to increase up to 642 million in 2040. Overall global prevalence is $34.6 \%$ [5], out of which diabetic retinopathy accounts for $4.8 \%$ of the cases of blindness around the world [6]. Diabetic retinopathy is a leading cause of new-onset blindness in populations of working age in developed countries, and an increasingly frequent cause of blindness in developing countries. Diabetic retinopathy is one of the leading causes of preventable blindness around the world [5]. It has been proven in the literature that there is direct link between duration of diabetes with diabetic retinopathy and micro vascular complications [7]. Therefore it is imperative to identify knowledge, attitude and practices of people with diabetes in developing countries. Given this the purpose of this study was to determine knowledge, attitude and practices of diabetic retinopathy in diagnosed diabetic patients.

\section{Material AND Methodology}

A Cross sectional Descriptive study was conducted form June 2019 to august. The study was conducted in district head quarter hospital of Sahiwal Pakistan. Convenient sampling technique was used to enroll the study participants. A self-structured, validated and reliable tool was developed and used to collect the data after pilot testing. Before using the tool validity and reliability of the tool was ensure. The cronbach alpha of the tool was 0.79 which showed a good value of a reliable tool. A detailed search in 
literature was done to create the knowledge, attitude and practice questionnaire. Questionnaire was tested in a sample group of representative population. All diagnosed diabetic patients and consented to participate in the study were included. Questionnaire consisted of four parts; first part contained the patient profile and demographic information which included name, gender, occupation, socioeconomic status and educational status. Second part included questions about knowledge of diabetes mellitus and diabetic retinopathy like duration, family history of diabetes and any eye complaints if present. Third part of the questionnaire include attitude towards diabetes and diabetic retinopathy like changes in daily life due to diabetes. Fourth part of questionnaire includes practices that patients follow due to diabetes and diabetic retinopathy. Patients above 35 years of age and diagnosed diabetic patients were included. Mentally retarded patients, who were not willing to participate and uncooperative patients were not included. Overall 72 patients participated in the study and data were completed from these patients. Data was analyzed using statistical package of social sciences SPSS version 24. Measure of central tendency and measure of dispersion was used including mean and standard deviation of knowledge score and frequencies of different part of the practice and attitude component.

\section{RESULTS \\ Knowledge}

Seventy two patients were included into the study, out of which $30(41.7 \%)$ were male and $42(58.3 \%)$ were female. The distribution of gender is presented in Figure 1.

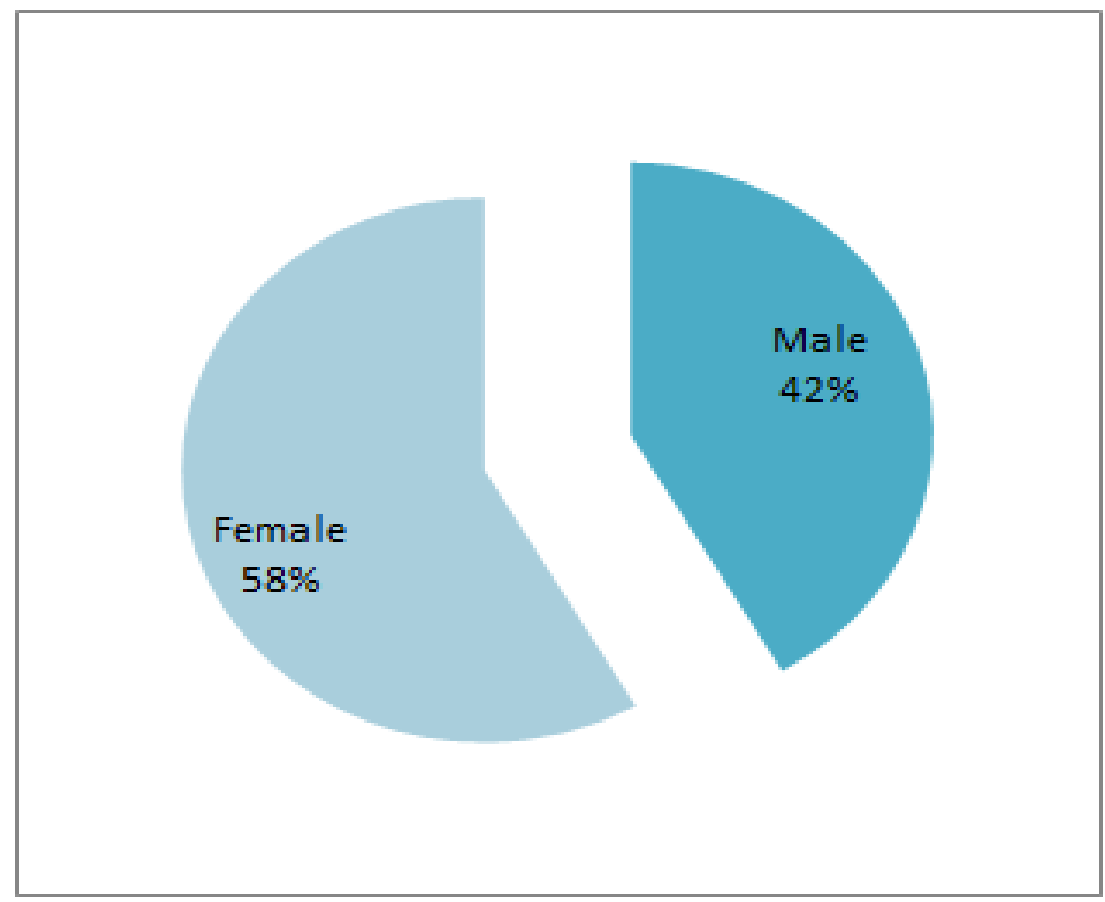

Fig-1: Gender distribution of participants $(\mathrm{N}=72)$

Patients with minimum age of 35 years were included, most of them were of age 46 to 50 years 25 (34.7\%), 35 to 40 years were $9(12.5 \%), 41$ to 45 years were $18(25.0 \%), 51$ to55 years were $13(18.1 \%), 56$ to 60 years were $5(6.9 \%)$ and above 61 years were 2 $(2.8 \%)$ patients. $34(47.2 \%)$ patients had diabetes from 1 to 5 years, 23 (31.9\%) had 6 to 10 years, $9(12.5 \%)$ had from 11 to 15 years, 3 (4.2\%) patients had from 16 to 20 years and $3(4.2 \%)$ patients had from above 20 years. $23(31.9 \%)$ patients had positive family history while $49(68.9 \%)$ had negative family history. Out of 72 , majority $42(58.3 \%)$ patients have no knowledge about diabetes while those who were aware about diabetes were asked further questions about symptoms, causes, complications and its related impacts on the health of eye. $22(30.6 \%)$ patients said yes diabetes affected their eyes, $2(2.8 \%)$ said no while $48(66.7 \%)$ patients didn't know. Out of 22 patients, 17 (77.27\%) said after 1 to 5 years eyes (vision) gets affected while 5 $(22.72 \%)$ said after 6 to 10 years. When patients were asked about the treatment of DR, $13(18.1 \%)$ patients said DR can be treated with injections, $1(1.4 \%)$ said surgery, $6(8.3 \%)$ said laser while $52(72.2 \%)$ patients didn't know about it (Table \# 1). 
Faryal Farooq \& Shahid Hussain Bapar., Saudi J Med Pharm Sci, Jan, 2021; 7(1): 15-19

Table-1: knowledge about Diabetic retinopathy $(\mathrm{N}=72)$

\begin{tabular}{|l|l|l|}
\hline Do you know about diabetes? & & \\
\hline 1.Yes & 30 & $41.7 \%$ \\
\hline 2.No & 42 & $58.3 \%$ \\
\hline Do you know how a person develops Diabetes? & & \\
\hline 1.Family History of Diabetes & 1 & $3.3 \%$ \\
\hline 2.Old age & 2 & $6.6 \%$ \\
\hline 3.Eating too much Sugar & 13 & $43.3 \%$ \\
\hline 4.Stress & 9 & $30.0 \%$ \\
\hline 5. Overeating(Hunger) & 5 & $16.6 \%$ \\
\hline 6.Smoking & - & - \\
\hline 7.Others & - & - \\
\hline What can be symptoms of Diabetes? & & \\
\hline 1.Excessive Urination & 9 & $30.0 \%$ \\
\hline 2.Excess Thirst & 1 & $3.3 \%$ \\
\hline 3.Tiredness & 15 & $50.0 \%$ \\
\hline 4.Loss of appetite & 3 & $10.0 \%$ \\
\hline 5.Weight loss & 1 & $3.3 \%$ \\
\hline 6.Vision problem & 1 & $3.3 \%$ \\
\hline 7.Genital Infections & - & - \\
\hline 9.Others & - & - \\
\hline Do you Know Diabetes affect your Eyes? & & \\
\hline 1.Yes & 22 & $30.6 \%$ \\
\hline 2.No & 2 & $2.8 \%$ \\
\hline 3. Don't know & 48 & $66.7 \%$ \\
\hline Do you Know the treatment of DR? & & \\
\hline 1.Medicine & - & - \\
\hline 2.Diet & - & - \\
\hline 3.Injection & 13 & $18.1 \%$ \\
\hline 4.Surgery & 1 & $1.4 \%$ \\
\hline 5.Laser & 6 & $8.3 \%$ \\
\hline 6.Don't Know & 52 & $72.2 \%$ \\
\hline & & \\
\hline
\end{tabular}

\section{Attitude}

Attitude of patients varies towards prevention of eye from diabetes as $18(25.0 \%)$ patients answered yes, 3(4.2\%) said no while 51(70.8\%) didn't know.

(Table \# 2).

Table-2: Attitude of patients toward diabetic retinopathy $(\mathrm{N}=72)$

\begin{tabular}{|l|l|l|}
\hline Do you know eye can be prevented from Diabetes? & & \\
\hline 1.Yes & 18 & $25.0 \%$ \\
\hline 2.No & 3 & $4.2 \%$ \\
\hline 3.Don't know & 51 & $70.8 \%$ \\
\hline If yes then how eye can be prevented from Diabetes? & & \\
\hline 1.Control of disease & 12 & $66.6 \%$ \\
\hline 2.Treatment & 4 & $22.2 \%$ \\
\hline 3.Medication & 2 & $11.1 \%$ \\
\hline
\end{tabular}

\section{Practices}

Out of 72 patients, $40(55.6 \%)$ patients answered yes they had regular follow up visits to their doctor and $32(44.4 \%)$ said no. For the control of diabetes $54(75.0 \%)$ patients said yes they follow the diet schedule while $17(23.6 \%)$ said no and $1(1.4 \%)$ patient were not sure about it. For the control of diabetes $10(13.9 \%)$ patients said yes they follow the exercise schedule and $62(86.1 \%)$ patients said no (Table \# 3). 
Faryal Farooq \& Shahid Hussain Bapar., Saudi J Med Pharm Sci, Jan, 2021; 7(1): 15-19

Table-3: Practices of patient toward diabetic retinopathy prevention $(\mathrm{N}=72)$

\begin{tabular}{|l|l|l|}
\hline Does your treatment plan have regular follow up visits to your doctor? & & \\
\hline 1.Yes & 40 & $55.6 \%$ \\
\hline 2. No & 32 & $44.4 \%$ \\
\hline Do you follow the diet schedule for the control of Diabetes? & & \\
\hline 1.Yes & 54 & $75.0 \%$ \\
\hline 2.No & 17 & $23.6 \%$ \\
\hline 3.Not Sure & 1 & $1.4 \%$ \\
\hline For the control of Diabetes do you follow the Exercise schedule? & & \\
\hline 1.Yes & 10 & $13.9 \%$ \\
\hline 2.No & 62 & $86.1 \%$ \\
\hline 3.Not Sure & - & - \\
\hline
\end{tabular}

\section{DISCUSSION}

Good knowledge was found in $30(41.7 \%)$ patients, $12(16.6 \%)$ male and $18(25 \%)$ female. Level of knowledge was low, positive attitude was also lower than desired level. While satisfactory level of practices regarding diet was noted in very high proportion of patients. Poor knowledge was due to illetracy and lack of awareness. While low level of practices regarding exercise as compared to diet is due to small living areas, load of work (as mostly were labor), foot pain and tiredness. Many patients didn't know the impact of diabetes on the eye.

In this study female showed more positive results of knowledge about diabetes than male. 18 $(25 \%)$ female patients have good knowledge about diabetes while 12(16.6\%) male patients. A study done in rural area of India showed knowledge of diabetes was significantly higher among women compared with men. Moreover it showed that a higher percentage of individuals having knowledge about DR were concerned for regular eye examination rather than those with no knowledge [9]. A study done on final year medical students of King Faisal university Medical college of Al Hasa region of Saudi Arabia. Results showed that man have better knowledge than female. Similarly male scored better in practice [14]. Quite similar results were found in study in Mongolia that showed one in five have never heard the term diabetes. Significantly more males reported no knowledge than females [15]. Similar study was made in South Indian state to assess the knowledge and practices about diabetes and DR. In their study good knowledge was observed in $55.6 \%$ and positive attitude were observed in $43.2 \%$. These results are quite similar to this, while results about practices showed marked differences. Good practices were observed in $48.14 \%$ while study done in south Indian state showed $57.6 \%$ have good practices [10]. Another study by Iran Mahtab Niroomand et al. observed $61.41 \%, 50.44 \%$ and $52.23 \%$ of good knowledge, attitude and positive attitude respectively and results are quite similar to the results of this study [11]. A study done in Nepal showed results in categories they made. It showed that $21.3 \%$ had highly insufficient, $22.5 \%$ had insufficient, $23 \%$ had sufficient $20.9 \%$ had satisfactory and $12.3 \%$ had highly satisfactory knowledge [12]. Another study conducted in Oman showed the results about KAP regarding eye complications and eye care. Excellent grade of knowledge was among $72.9 \%$ and eye care was $18 \%$. Similarly excellent grade of attitude about eye care was found in $29.9 \%$. The practice for undergoing eye checkup and accepting treatment was $52 \%$ and $79.2 \%$ respectively [13]. Study done in two states of Nigeria showed $79.5 \%$ had knowledge about self care. Self care was associated with level of education, monthly income and duration of diabetes. Negative attitude towards disease was only factor associated with knowledge [16]. A study conducted in Bangladesh showed quite different results where knowledge and attitude did not differ in male and female, but the practice score of male was significantly higher than female. No influence of occupation was found in knowledge and attitude but occupation had significant influence in practices [17].

\section{Conclusions}

In this study, knowledge about diabetes was not as satisfied as it should be. Knowledge about Diabetic retinopathy was even lower than diabetes. As patients are the most important decision makers, they should receive enough instructions to make informed decisions about prevention and management. Education can be more effective when it is educated according to knowledge, attitude and practices of patients. Results for practices were totally different. Practices for controlling diabetes regarding diet was good but regarding exercise showed poor results. Results showed that we need to propagate aggressive and comprehensive awareness models to educate about the importance of diet and exercise for prevention.

\section{RECOMMENDATIONS}

- Health worker should have knowledge about diabetes so they may communicate among patients in general community.

- Treatment outcome of Diabetic retinopathy also needs to be improved.

- Diabetologist should make aware and guide patients. 
- $\quad$ IEC should be made aware about diabetes and they should have leaflets to distribute among patients

- Services of treatment should be available at the district and Tehsil level.

- Development of primary health care programmes to increase knowledge of diabetes and its complications is required to assist people in rural area for the control and management of diabetes.

- People should be made aware about the importance of diet control and exercise.

- Awarness about diabetes and DR should be spread by delivering pumflets in community, or by camping.

- Seminars should be arranged to make aware about the importance of control of diabetes.

\section{REFRENCES}

1. https://www.niddk.nih.gov/healthinformation/diabetes/overview/what-is-diabetes National Institute of diabetes and digestive and kidney diseases

2. https://www.mayoclinic.org/diseaseconditions/diabetic-retinopathy/symptomscauses/syc-20371611 Mayoclinic

3. World Health Organization. (2014). Visual impairement and blindness Fact sheet $\mathrm{N}^{\mathrm{o}} 282$. [2014 Aug 9]. https://www.who.int/mediacentre/factsheet/fs282/e n.

4. International Diabetes Federation. (2015). IDF Diabetes Atlas. 7th edn. Brussels, Belgium: International Diabetes Federation. http://www.diabetesatlas.org.

5. Yau, J. W., Rogers, S. L., Kawasaki, R., Lamoureux, E. L., Kowalski, J. W., Bek, T., ... \& Haffner, S. (2012). Global prevalence and major risk factors of diabetic retinopathy. Diabetes care, 35(3), 556-564.

6. Resnikoff, S., Pascolini, D., Etya'Ale, D., Kocur, I., Pararajasegaram, R., Pokharel, G. P., \& Mariotti, S. P. (2004). Global data on visual impairment in the year 2002. Bulletin of the world health organization, 82, 844-851.

7. Klein, R., Klein, B. E., \& Moss, S. E. (1989). The Wisconsin epidemiological study of diabetic retinopathy: a review. Diabetes/metabolism reviews, 5(7), 559-570.

8. Memon, M. S., Shaikh, S. A., Shaikh, A. R., Fahim, M. F., Mumtaz, S. N., \& Ahmed, N. (2015). An assessment of knowledge, attitude and practices (KAP) towards diabetes and diabetic retinopathy in a suburban town of Karachi. Pakistan journal of medical sciences, 31(1), 183.

9. Rani, P. K., Raman, R., Subramani, S., Perumal, G., Kumaramanickavel, G., \& Sharma, T. (2008). Knowledge of diabetes and diabetic retinopathy among rural populations in India, and the influence of knowledge of diabetic retinopathy on attitude and practice.

10. Hussain, R., Rajesh, B., Giridhar, A., Gopalakrishnan, M., Sadasivan, S., James, J., ... \& John, N. (2016). Knowledge and awareness about diabetes mellitus and diabetic retinopathy in suburban population of a South Indian state and its practice among the patients with diabetes mellitus: A population-based study. Indian Journal of ophthalmology, 64(4), 272.

11. Mahtab, N. (2016). Science Direct. 2016 Diabetes KAP study among Iranian in patients with Diabetes type II: A cross sectional study.

12. Anju, G. (2015). BMC Endocrine Disorders. 2015. Diabetes related health KAP among diabetic patients in Nepal.

13. Rajiv, K. (2008). Oman J of Ophthalmology. KAP regarding eye complication and care among Omani persons with diabetes - A cross sectional study.

14. FA, Al. Wadaani. (2013). Nigerian J of Clinical Practice. 2013. The KAP regarding diabetes and diabetic retinopathy among the final year medical students of king Faisal University Medical College of Al Hasa region of Saudi Arabia: A cross sectional survey.

15. Alessandro, R. (2013). BMC public health. 2013. Exploring KAP related to diabetes in Mongolia: a national population-based survey.

16. Idongesit, L. Jackson. (2013). Pharmacy Practice. Know3edge of self-care among type 2 diabetes patients in tw6 states of Nigeria.

17. Farzana, S. (2012). J Public Health Africa. 2012. KAP of type 2 diabetic Patients regarding Obesity: Study in a tertiary care hospital in Bangladesh. 